Skinner, F. A. (1956). J. gen. Microbiol. 14, 393-405

\title{
The Effect of Adding Clays to Mixed Cultures of Streptomyces albidoflavus and Fusarium culmorum
}

\author{
By F. A. SKINNER \\ Soil Microbiology Department, Rothamsted Experimental Station, Harpenden, \\ Hertfordshire
}

SUMMARY: An antibiotic present in culture filtrates of Streptomyces albidoflavus was inactivated by clays and by suspensions and extracts of soils. When this actinomycete was grown with Fusarium culmorum in a sand + bentonite mixture moistened with nutrient solution, it did not antagonize the fungus by antibiotic secretions. However, suppression of fungus growth was observed even in the presence of bentonite particularly when glucose was present in abundance; this effect was attributed to competition between the organisms for limiting nutrients. The actinomycete also lysed the contents of the fungus mycelium in sand culture but not when bentonite was added. The lytic agent appeared to differ from the antibiotic. Neither antibiotic action nor direct (lytic) attack on the fungus was demonstrated in sterilized soil.

In a previous paper (Skinner, 1956) the complexity of the relationship between Streptomyces albidoflavus and Fusarium culmorum was indicated. In sand culture the growth of the fungus was suppressed by antibiotic secretions of the actinomycete and preformed fungus mycelium was destroyed. Even when glucose concentrations were low, some inhibition of fungus growth by the actinomycete was observable, but it was not clear whether this was due to the presence of antibiotic substances or to competition for limiting nutrients. There are many factors in sterile and in unsterile soil which tend to inactivate antibiotics which have been added or formed in situ (Brian, 1949; Siminoff \& Gottlieb, 1951 ; Gottlieb \& Siminoff, 1952; Jefferys, 1952). In particular, clays frequently adsorb basic antibiotics which are elaborated by the majority of antibiotic-producing Streptomyces spp., and render them inactive. In view of this it was considered that the inclusion of clays in mixed sand cultures might well eliminate antibiotic effects and so permit some distinction to be made between (a) inhibition of growth of Fusarium culmorum caused by antibiotic actinomycete secretions; $(b)$ limitation of growth of this fungus because of nutrient deficiencies brought about by growth of the actinomycete.

The micro-organisms, materials and methods were generally the same as described in the preceding paper (Skinner, 1956); techniques peculiar to this paper are described at appropriate places in the text.

\section{RESULTS}

Inactivation of the antibiotic formed by Streptomyces albidoflavus in culture filtrates

Test-tubes, each containing $5 \mathrm{ml}$. of glucose asparagine solution buffered at pH 7.0 (M/15 KH $\mathrm{KHO}_{4}$ soln., $195 \mathrm{ml}$.; $\mathrm{M} / 15 \mathrm{Na}_{2} \mathrm{HPO}_{4}$ soln., $305 \mathrm{ml}$.; glucose, $10 \mathrm{~g}$.; asparagine $0.5 \mathrm{~g}$.; distilled water to 11 .) were sterilized by steaming for 
$20 \mathrm{~min}$. on each of three consecutive days, inoculated with spores of Streptomyces albidoflavus and incubated at $\mathbf{2 5}^{\circ}$. After 8 days, the cultures were divided into two sets. One set remained untreated (untreated tubes). 'The contents of tubes of the second set were bulked, filtered through a sterile no. 5 filter-paper and the filtrate redistributed in $5 \mathrm{ml}$. portions into sterile tubes. These tubes were then immersed in boiling water for 2 min., and then cooled rapidly in cold water (filtrate tubes). Duplicate tubes of each set then received sterile additions of bentonite or kaolin suspended in $1 \mathrm{ml}$. fresh medium (see Table 1). Control tubes did not receive the clays. Each tube was then inoculated with spores of Fusarium culmorum and incubated.

Table 1. Growth of Fusarium culmorum in liquid cultures and culture filtrates of Streptomyces albidoflavus

\begin{tabular}{|c|c|c|c|c|c|}
\hline \multirow{3}{*}{ Material added } & \multirow{3}{*}{$\begin{array}{c}\text { Amount } \\
\text { added/tube } \\
\text { (mg.) }\end{array}$} & \multirow[b]{3}{*}{ Kind of culture } & \multicolumn{3}{|c|}{$\begin{array}{l}\text { Relative amount of } \\
\text { fungal growth }\end{array}$} \\
\hline & & & \multicolumn{3}{|c|}{ Period of incubation (days) } \\
\hline & & & 2 & 7 & 16 \\
\hline Control (no addition) & - & $\begin{array}{l}\text { Untreated } \\
\text { Filtrate }\end{array}$ & - & $\begin{array}{l}- \\
-\end{array}$ & $\begin{array}{l}- \\
-\end{array}$ \\
\hline \multirow[t]{2}{*}{ Bentonite } & 1 & $\begin{array}{l}\text { Untreated } \\
\text { Filtrate }\end{array}$ & $\begin{array}{l}++ \\
++\end{array}$ & $\begin{array}{l}++ \\
++\end{array}$ & $\begin{array}{l}++ \\
++\end{array}$ \\
\hline & 10 & $\begin{array}{l}\text { Untreated } \\
\text { Filtrate }\end{array}$ & $\begin{array}{l}++ \\
++\end{array}$ & $\begin{array}{l}++ \\
++\end{array}$ & $\begin{array}{l}++ \\
++\end{array}$ \\
\hline \multirow[t]{2}{*}{ Kaolin } & 10 & $\begin{array}{l}\text { Untreated } \\
\text { Filtrate }\end{array}$ & - & $\overrightarrow{+}$ & - \\
\hline & 100 & $\begin{array}{l}\text { Untreated } \\
\text { Filtrate }\end{array}$ & - & - & - \\
\hline
\end{tabular}

$-=$ no growth of fungus; $+=$ trace of fungal growth; $++=$ good growth of fungus (mycelium occupying at least $\frac{1}{4}$ volume of culture).

During the first 2 days the fungus grew only in tubes containing bentonite. Fungus growth appeared in the filtrate tubes without clay after 3 weeks; this was attributed to decay of the inhibitor. The fungus did not grow in the untreated controls; in this set the concentration of antibiotic was presumably maintained by continued growth of the actinomycete. The fungus began to grow between the 2 nd and 7 th days in filtrate tubes which contained kaolin. Probably the kaolin adsorbed some antibiotic, but not enough to decrease the initial concentration quickly to a value at which fungus growth could begin. However, this critical concentration was apparently reached by decay of the remaining unadsorbed antibiotic after a short time.

Bentonite (1 mg.) also inactivated the antibiotic produced in $5 \mathrm{ml}$. of ASP solution E containing $10 \mathrm{~g}$. glucose/l. (see p. 395).

Two Rothamsted clays (one derived from soil of Broadbalk field plot 3, and the other from soil of the meteorological enclosure) and three soils (Broadbalk plot 2, and an Australian chernozem and laterite) also inactivated the antibiotic when tested in the same way at rates of $10 \mathrm{mg}$. and $100 \mathrm{mg}$./tube of $5 \mathrm{ml}$. of 
liquid culture or culture filtrate, though none of these was nearly so effective as bentonite. Besides the tubes which received suspensions of the three soils, duplicate sets of tubes received $1 \mathrm{ml}$. portions of centrifuged sterile extracts prepared from $10 \mathrm{mg}$. or $100 \mathrm{mg}$. of soil $/ \mathrm{ml}$. extracting glucose asparagine solution. These extracts were also effective in inactivating the antibiotic, though generally to a lesser degree than the corresponding suspensions. The activity of these extracts was probably due to the organic matter in the soils (Skinner, 1956). The effectiveness of bentonite in inactivating the antibiotic suggested that bentonite would be a suitable material for adding to mixed cultures of the two organisms in order to eliminate antibiotic effects.

\section{Flask culture experiments}

Sand and sand + clay mixtures in flasks were moistened with an artificial soil solution supplemented with different concentrations of glucose. The artificial soil solution (hereafter ASP solution) had the following composition (g./l. distilled water): $\mathrm{CaSO}_{4}, 0 \cdot 8 ; \mathrm{Ca}\left(\mathrm{NO}_{3}\right)_{2}, 0.33 ; \mathrm{MgSO}_{4} \cdot 7 \mathrm{H}_{2} \mathrm{O}, 0 \cdot 7 ; \mathrm{K}_{2} \mathrm{SO}_{4}, 0 \cdot 025$; $\mathrm{K}_{2} \mathrm{HPO}_{4}, 0 \cdot 5 ; \mathrm{NaHCO}_{3}, 0 \cdot 2 ; \mathrm{FeCl}_{3}$, trace. This solution, with glucose additions, was sterilized by steaming for $20 \mathrm{~min}$. on three consecutive days; the $\mathrm{pH}$ value

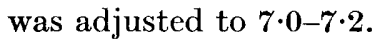

An experiment was made to determine whether Streptomyces albidoflavus would inhibit the growth of Fusarium culmorum in sand cultures containing clays or silt. Nine sets of $50 \mathrm{ml}$. flasks (4 flasks/set) were prepared. The flasks of each set contained one of the following mixtures: (1) $10 \mathrm{~g}$. sand; (2) $9 \cdot 9 \mathrm{~g}$. sand $+0 \cdot 1 \mathrm{~g}$. bentonite; (3) $9 \mathrm{~g}$. sand $+1 \mathrm{~g}$. bentonite; (4) $9 \cdot 9 \mathrm{~g}$. sand $+0 \cdot 1 \mathrm{~g}$. kaolin; (5) 9 g. sand +1 g. kaolin; (6) $9 \cdot 9$ g. sand $+0 \cdot 1$ g. Broadbalk clay; (7) 9 g. sand +1 g. Broadbalk clay; (8) $9 \cdot 9$ g. sand $+0 \cdot 1$ g. Broadbalk silt; (9) $9 \mathrm{~g}$. sand $+1 \mathrm{~g}$. Broadbalk silt. Two flasks of each set received spores of Streptomyces albidoflavus suspended in $1 \mathrm{ml}$. of ASP solution containing $10 \mathrm{~g}$. glucose/l.; and were incubated at $25^{\circ}$. The remaining two flasks of each set (controls) were not inoculated. After 5 days of incubation each flask was inoculated with spores of Fusarium culmorum suspended in $1 \mathrm{ml}$. of medium. The incubation of the cultures was then continued and the flasks were examined at intervals.

The actinomycete completely inhibited fungus growth in sets 1, 8 and 9 which had no additions of clays, but did not do so in the flasks of the remaining sets. In most of these clay cultures, the fungus grew to some extent after only 1 day of incubation. It was, however, obvious that fungus mycelium in the presence of the actinomycete in these clay cultures was not nearly so abundant as it was in the corresponding control cultures without the actinomycete.

Quantitative measurements were made of fungus growth in sand cultures set up as in the foregoing experiment. Two sets of culture flasks were prepared; those of one set each contained $10 \mathrm{~g}$. of sand; those of the other set, $10 \mathrm{~g}$. of sand + bentonite mixture (100 $\mathrm{mg}$. bentonite). Three replicates of each set were incubated at $\mathbf{2 5}^{\circ}$ and one of them was used for each sampling. During incubation each flask received $0.5 \mathrm{ml}$. sterile water weekly to make up 
evaporation loss. Estimates of numbers of fragments of fungus mycelium and spores were made by the method already described (Skinner, 1956). The actinomycete completely inhibited fungus growth in cultures without bentonite and attacked the spores added as inoculum (Table 2). These spores became enveloped in actinomycete mycelium and rapidly lost their staining properties. In the older cultures fungus spores were not detected, either because they had

Table 2. Growth of Fusarium culmorum with Streptomyces albidoflavus in sand and sand +bentonite moistened with ASP solution containing $10 \mathrm{~g}$. glucose/l.

\begin{tabular}{|c|c|c|c|c|c|c|c|}
\hline & & & No. fung: & $\begin{array}{l}\text { spores a } \\
\left.10^{3}\right) / g \cdot d\end{array}$ & $\begin{array}{l}\text { ad hyphal } \\
\text { y wt. cul }\end{array}$ & $\begin{array}{l}\text { fragmen } \\
\text { ure }\end{array}$ & \\
\hline & & Period o & $f$ incubati & n after ir & oculation & with fur & gus (days) \\
\hline & & & $\mathbf{3}$ & 1 & & & \\
\hline & & Spores & Hyphae & Spores & Hyphae & Spores & Hyphae \\
\hline Sand & $\begin{array}{l}F . \text { culmorum } \\
\text { alone }\end{array}$ & $23 \cdot 7$ & $184 \cdot 8$ & $105 \cdot 4$ & $250 \cdot 2$ & $178 \cdot 9$ & $335 \cdot 2$ \\
\hline & $\begin{array}{r}F . \text { culmorum }+ \\
\text { actinomycete }\end{array}$ & $1 \cdot 24 *$ & 0 & $0 \cdot 38 \dagger$ & 0 & $\mathbf{0}$ & 0 \\
\hline $\begin{array}{l}\text { Sand }+ \\
\text { bentonite }\end{array}$ & $\begin{array}{l}\text { F. culmorum } \\
\text { alone }\end{array}$ & $41 \cdot 2$ & $163 \cdot 2$ & $150 \cdot 4$ & $307 \cdot 1$ & $273 \cdot 7$ & $272 \cdot 7$ \\
\hline$(1 \%, w / w)$ & $\begin{array}{c}F \cdot \text { culmorum }+ \\
\text { actinomycete }\end{array}$ & 0 & $20 \cdot 1$ & $1 \cdot 1$ & $86 \cdot 9$ & $8 \cdot 1$ & 143.5 \\
\hline
\end{tabular}

been completely destroyed or were hidden in the mass of actinomycete mycelium. Spores were not attacked in this way when bentonite was present. However, the fungus made much less growth in the presence of the actinomycete, even in the flasks containing $100 \mathrm{mg}$. bentonite. Since $1 \mathrm{mg}$. bentonite inactivated the antibiotic produced in $5 \mathrm{ml}$. liquid, actinomycete culture or heated culture filtrate, prepared either with buffered glucose asparagine solution or with ASP solution E, it may be assumed that the $100 \mathrm{mg}$. bentonite present in the $10 \mathrm{~g}$. sand + bentonite cultures was more than adequate to inactivate any antibiotic formed from the $2 \mathrm{ml}$. of ASP solution contained in such cultures. It is therefore reasonable to attribute the suppression of fungus growth in such cultures (as compared with the fungus growth in the sand + bentonite control cultures without the actinomycete) to competition between the two organisms for some limiting nutrient.

It might be objected that an antibiotic may be adsorbed on a colloid yet still retain some activity. This was found by Pramer \& Starkey (1950), who observed that when soil which had adsorbed streptomycin was added to agar medium, the antibiotic still exerted its effects on bacteria inoculated on to the agar surface. Thus, it would be expected that micro-organisms in soil in direct contact with particles with adsorbed streptomycin would be influenced by this antibiotic. 
An experiment was made to determine whether the Streptomyces albidoflavus antibiotic remained similarly active when adsorbed on bentonite. Plates of ASP solution agar containing $1.5 \%(\mathrm{w} / \mathrm{v})$ bentonite were streak-inoculated with spores of $S$. albidoflavus, incubated at $25^{\circ}$ for 5 days and then inoculated with Fusarium culmorum at a distance of $3 \mathrm{~cm}$. from the actinomycete growth. On these plates the fungus grew steadily towards the actinomycete and made contact with it within 7 days, whereas on similar plates without bentonite fungus growth was arrested at a distance from the actinomycete. Similar results were obtained on glucose asparagine agar with and without bentonite. In these cultures, the fungus grew well in intimate contact with particles of bentonite which must have adsorbed the antibiotic. Thus the evidence was against the possibility that bentonite charged with the Streptomyces albidoflavus antibiotic would suppress growth of Fusarium culmorum in contact with it.

Inhibition of fungus growth in sand and sand +bentonite cultures in media. with low glucose concentrations

It had been found that the growth of Fusarium culmorum was inhibited slightly, even in sand moistened with medium containing low concentrations of glucose (Skinner, 1956). An experiment was therefore made to determine whether inhibition at such low glucose concentrations might be attributed to antibiotic action. Flask cultures containing sand or sand + bentonite mixture were prepared and inoculated with Streptomyces albidoflavus spores contained

Table 3. Growth of Fusarium culmorum with Streptomyces albidoflavus in sand and sand + bentonite moistened with ASP solution

\begin{tabular}{|c|c|c|c|c|}
\hline & & & & \\
\hline Medium & Type of culture & $\begin{array}{l}\text { Actino- } \\
\text { mycete }+ \\
\text { fungus } \\
\text { (No. frag } \\
\text { mycelium } \\
\text { wt. }\end{array}$ & $\begin{array}{l}\text { Control } \\
\text { (fungus } \\
\text { alone) } \\
\text { s fungus } \\
\left.0^{3}\right) / g \text {. dry } \\
\text { (re) }\end{array}$ & $\begin{array}{c}\text { Ratio } \\
\text { control: } \\
\text { mixed } \\
\text { culture }\end{array}$ \\
\hline B $(0.001 \%$ glucose $)$ & $\begin{array}{l}\text { Sand } \\
\text { Sand + bentonite }\end{array}$ & $\begin{array}{r}7 \cdot 4 \\
11 \cdot 9\end{array}$ & $\begin{array}{l}26 \cdot 9 \\
19 \cdot 5\end{array}$ & $\begin{array}{l}3 \cdot 64 \\
1 \cdot 64\end{array}$ \\
\hline $\mathrm{C}(0.01 \%$ glucose $)$ & $\begin{array}{l}\text { Sand } \\
\text { Sand + bentonite }\end{array}$ & $\begin{array}{r}9 \cdot 4 \\
25 \cdot 6\end{array}$ & $\begin{array}{l}41 \cdot 2 \\
28 \cdot 9\end{array}$ & $\begin{array}{l}4 \cdot 38 \\
1 \cdot 13\end{array}$ \\
\hline $\mathrm{D}(0.1 \%$ glucose $)$ & $\begin{array}{l}\text { Sand } \\
\text { Sand + bentonite }\end{array}$ & $\begin{array}{r}6 \cdot 2 \\
12 \cdot 4\end{array}$ & $\begin{array}{l}79 \cdot 2 \\
66 \cdot 5\end{array}$ & $\begin{array}{r}12 \cdot 77 \\
5 \cdot 36\end{array}$ \\
\hline
\end{tabular}

in $1 \mathrm{ml}$. portions of ASP solution media B, C and D containing respectively $0 \cdot 01,0 \cdot 1$ and $1 \cdot 0 \mathrm{~g}$. glucose/ 1 . The flasks were incubated for 5 days before inoculation with $\boldsymbol{F}$. culmorum spores. The amounts of fungus mycelium were estimated after a further day of incubation. Some inhibition of fungus growth took place in all cultures containing the actinomycete (Table 3), although bentonite again decreased the degree of inhibition (as indicated by the ratio of control: test estimates). 
In media $\mathrm{B}$ and $\mathrm{C}$ (low glucose concentrations) the actinomycete greatly decreased fungus growth in sand alone, but this inhibitory effect was almost removed by the presence of bentonite, suggesting that inhibition was here due almost wholly to antibiotic effect. But in medium D (high glucose), the actinomycete produced in sand + bentonite a degree of inhibition nearly half that shown in sand alone. Thus in a strongly growing culture of Streptomyces albidoflavus only part of the inhibition could be attributed to antibiotic action. This suggests that the inhibition of the fungus was partly due to competition by the actinomycete for some limiting nutrient and that this competition became important only when there was sufficient growth to use up the supply of this nutrient. The occurrence of very slight inhibitory effects in sand or sand + bentonite mixture moistened with media $\mathbf{B}$ and $\mathrm{C}$ was confirmed by a repeat experiment in which estimates were made on duplicate flasks.

In the experiments with media containing only low concentrations of glucose, Streptomyces albidoflavus had grown for $\mathbf{5}$ days before inoculation with Fusarium culmorum. Estimates of fungus growth were made shortly after this inoculation in an attempt to record any inhibitory effects due to the previous growth of the actinomycete. In another experiment the course of the competition was followed for a longer period of incubation and the effects of simultaneous inoculation with both organisms were observed. In order to do this it was necessary to add small quantities of glucose to the cultures at intervals in order to compensate for its removal by the growing organisms.

Twenty-four culture flasks were prepared: twelve flasks each contained $10 \mathrm{~g}$. sand, and twelve flasks, $10 \mathrm{~g}$. sand + bentonite mixture ( $1 \%$ bentonite). After sterilization the flasks were divided into two sets, each consisting of six sand flasks and six sand + bentonite flasks. Each flask received an addition of medium as follows: set $1-1 \mathrm{ml}$. ASP solution containing $10 \mathrm{~g}$. glucose/l.; set 2-1 ml. ASP solution $+0 \cdot 1 \mathrm{ml}$. glucose solution ( $1 \mathrm{~g}$. glucose $/ \mathrm{l}$.). Each flask in set 2 also received a further addition of $0.1 \mathrm{ml}$. of glucose solution ( $1 \mathrm{~g} . / \mathrm{l}$.) after 3, 6, 8, 12 and 16 days of incubation. Control cultures were inoculated with Fusarium culmorum alone, and mixed cultures were set up by two methods. In the first method $9 \cdot 9 \times 10^{3}$ Streptomyces albidoflavus spores/ flask were supplied at the start and incubated for 5 days at $25^{\circ}$ before Fusarium culmorum was introduced at the rate of $4.39 \times 10^{4}$ spores/flask (series B). In the second method (series A) the two inocula were supplied at the same time (Table 4). To compensate for evaporation loss, $0.5 \mathrm{ml}$. sterile water was added to each flask weekly. Observations were made on duplicate flasks at intervals and direct count estimates of fungus growth made on one flask of each pair.

When the actinomycete was given a 5-day start (series B), it inhibited fungus growth in sand alone at both glucose concentrations, but inhibition was most marked (by comparison with the corresponding control cultures of series A) at the higher glucose concentration. At the lower glucose concentration, the presence of bentonite had no effect by 7 days in decreasing inhibition, but later, growth of the fungus recovered to about half that produced without the actinomycete and so growth was maintained. At the higher glucose concentration, the actinomycete kept down the fungal growth even in the presence of 

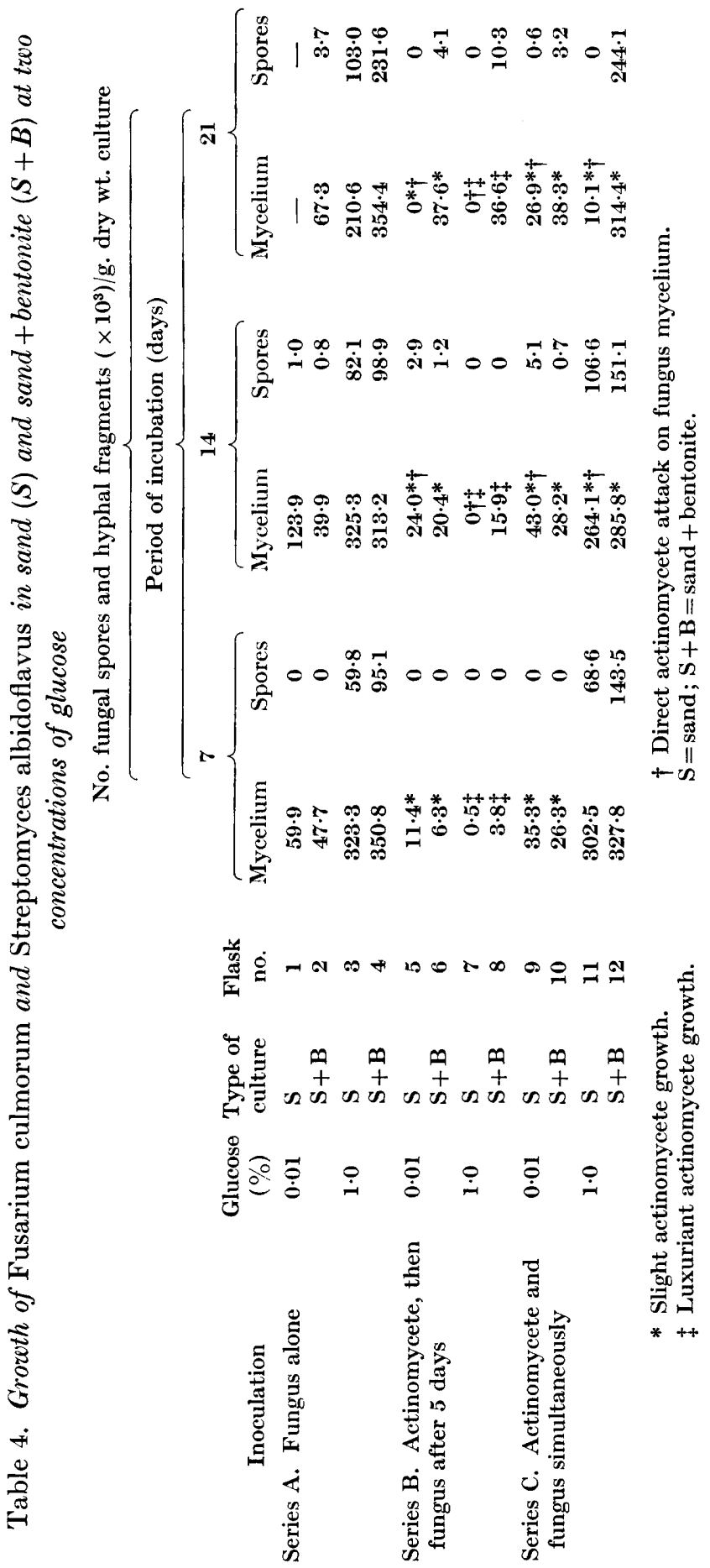
bentonite, the number of mycelial fragments never exceeding $10 \cdot 33 \%$ of those in the cultures without the actinomycete.

When both organisms were inoculated simultaneously (series C), the fungus outgrew the actinomycete at first in the sand and in the sand + bentonite cultures at the higher glucose concentration (flasks 11 and 12) so no effects of the antibiotic were discerned. Later the actinomycete developed on the fungus mycelium and destroyed it (or at least its contents) in the sand cultures (cf. flask 7). This attack did not develop when bentonite was present, although the actinomycete was as abundant as in the sand cultures (flask 11). At the lower glucose concentration the fungus did not outgrow the actinomycete at the start and the fungus was suppressed by comparison with the control cultures (flasks 1 and 2), though to a lesser extent than in those cultures where the actinomycete had grown first (flasks 5 and 6). Again, bentonite had little effect on the degree of inhibition of the fungus but it did prevent the direct attack by the actinomycete which was beginning by 14 days in the sand cultures (flask 9).

Chemical tests made at the third sampling time showed some reducing sugar in all the flasks. In the cultures containing the higher concentration of glucose no nitrate or nitrite was detected, but all low concentration glucose cultures gave a strong positive test for nitrite, but no nitrate was found. In this experiment the number of actinomycete spores added to each test flask was small compared with the number of fungus spores added. This small inoculum of actinomycete did not prevent its rapid and luxuriant development, with consequent severe inhibition of fungus growth when the actinomycete was allowed to grow for 5 days before fungus inoculation in cultures moistened with medium containing $10 \mathrm{~g}$. glucose/l. (flasks 7 and 8 ). However, though the actinomycete spores germinated rapidly in the corresponding cultures in flasks 5 and 6 which contained medium of low glucose concentration, actinomycete growth was poor and there was negligible inhibition of fungus growth either by antibiotic action or by competition for nutrients. It was considered that these competitive effects might have been more severe if the original actinomycete inoculum had been much larger. This was found to be the case in a repeat experiment in which a larger inoculum of actinomycete spores was used in cultures set up in the same way as those of set 2 in the previous experiment. The numbers of viable fungus particles increased steadily in the test flasks, in spite of the fact that the actinomycete numbers were also increasing during the same period. These increases in viable actinomycete count were due to vegetative growth since no aerial spore-bearing mycelium was observed on the sand particles; neither were spores found by microscopic examination. Nevertheless, greater fungus development was found in the control cultures than in the test cultures, although there was no initial retardation of fungus growth in the test cultures as had been observed on previous occasions when actinomycete development had been relatively much greater. The limitation of fungus growth in the test flasks was greater than had been found in similar flasks of the previous experiment, and it was considered that this limitation could be explained by a scarcity of nutrients caused by the growth of the 
actinomycete. This effect had not occurred in the previous experiment when the actinomycete inoculum was much smaller.

\section{Competition effects in sterilized soil}

Two sets of culture flasks were prepared : those of one set each contained $10 \mathrm{~g}$. air-dried Broadbalk (Rothamsted) soil in aggregates of 1-2 mm. diameter. Each flask of the other set contained $10 \mathrm{~g}$. of similar sized aggregates of soil + bentonite mixture prepared by mixing $1 \%(\mathrm{w} / \mathrm{w})$ bentonite intimately with powdered soil, mixing the whole with just sufficient water to make a stiff paste, drying and sifting. Incorporation of this amount of bentonite had no appreciable effect on the soil $\mathrm{pH}$ value. Mixed culture flasks of each set each received $1 \mathrm{ml}$. aqueous suspension of Streptomyces albidoflavus spores and each control flask $1 \mathrm{ml}$. sterile water. This volume of water was insufficient to wet all the soil but was the optimum required to ensure efficient distribution of the spores among the soil crumbs. After thorough mixing of the wet inoculated crumbs with the dry crumbs (by tapping the flasks on a rubber pad) $1.5 \mathrm{ml}$. water was added to each flask to bring the moisture content up to a value favourable for actinomycete and fungus growth. After 5 days of incubation each flask was inoculated with $1 \mathrm{ml}$. suspension of Fusarium culmorum spores distributed as drops over the undisturbed soil surface since the soil was then too wet to mix by agitation. Estimates of growth of the organisms were made at intervals by plate counts. Two flasks were used to make plate count estimates of fungus and actinomycete growth and observations were made on the third flask; whole flasks were used to make the suspension for plate counting. Actinomycetes were estimated by plating on starch-Tryptone agar $(\mathrm{pH} 7 \cdot 0)$ and fungi by plating on potato-glucose agar ( $\mathrm{pH} 4.5$ ), a medium on which the actinomycete did not grow.

Some inhibition of fungus growth occurred in all the mixed cultures (Table 5). There was no reasonable doubt that the $100 \mathrm{mg}$. bentonite present

Table 5. Growth of Fusarium culmorum and Streptomyces albidoflavus in sterilized soil

\begin{tabular}{|c|c|c|c|c|c|c|}
\hline & & \multirow{2}{*}{$\begin{array}{c}\text { Initial } \\
\text { inoculum } \\
\text { (no. viable } \\
\text { particles) }\end{array}$} & \multicolumn{4}{|c|}{$\begin{array}{l}\text { Period of incubation after } \\
\text { inoculation with fungus (days) }\end{array}$} \\
\hline & & & 0 & 6 & 13 & $\mathbf{3 6}$ \\
\hline & & \multicolumn{5}{|c|}{ No. viable fungus particles $\left(\times 10^{3}\right) /$ flask } \\
\hline Soil & $\begin{array}{l}\mathbf{A}+\mathbf{F} \\
\mathbf{F}\end{array}$ & $\begin{array}{l}15 \cdot 3 \\
15 \cdot 3\end{array}$ & - & $\begin{array}{r}12 \cdot 1 \\
912.5\end{array}$ & $\begin{array}{r}22 \cdot 5 \\
4000\end{array}$ & $\begin{array}{r}62 \cdot 6 \\
4331\end{array}$ \\
\hline \multirow[t]{2}{*}{ Soil + bentonite } & $\begin{array}{l}\mathbf{A}+\mathbf{F} \\
\mathbf{F}\end{array}$ & $\begin{array}{l}15 \cdot 3 \\
15 \cdot 3\end{array}$ & - & $\begin{array}{r}10 \cdot 2 \\
793 \cdot 8\end{array}$ & $\begin{array}{r}30 \cdot 6 \\
3363\end{array}$ & $\begin{array}{r}68 \cdot 3 \\
3263\end{array}$ \\
\hline & & \multicolumn{5}{|c|}{ No. viable actinomycete particles $\left(\times 10^{6}\right) /$ flask } \\
\hline Soil & & $0 \cdot 1$ & $84 \cdot 9$ & $370 \cdot 4$ & $412 \cdot 8$ & $451 \cdot 3$ \\
\hline Soil + bentonite & & $0 \cdot 1$ & $75 \cdot 4$ & $237 \cdot 1$ & $308 \cdot 1$ & $417 \cdot 2$ \\
\hline
\end{tabular}


in each soil + bentonite culture inactivated any antibiotic formed by the actinomycete from nutrients naturally present in the soil; consequently, suppression of fungus development in these mixed cultures was attributed to competition between the organisms for nutrients or for space. However, since the numbers of fungus particles in the mixed cultures in soil + bentonite were at all times comparable with those in the mixed cultures in soil, it was concluded that the conditions in both kinds of cultures were similar, and that the amount of soil present $(10 \mathrm{~g}$.) was itself adequate to inactivate antibiotic produced by the actinomycete.

The severity of inhibition of fungus growth in this experiment may, perhaps, be explained by rapid exhaustion of nutrients in the surface layers of the soil crumbs by the actinomycete even though the deeper parts might still perhaps contain a reserve of nutrient materials. In neither type of test culture was there evidence that the actinomycete had attacked the fungus directly. This direct attack was further investigated.

The existence of a lytic actinomycete secretion was demonstrated on solid media. Eight different agar media were prepared with and without added clays (Table 6). One Petri dish of each medium was inoculated with Fusarium culmorum and incubated. After 13 days, three standardized colonies of Streptomyces albidoflavus (Skinner, 1950) were prepared on each plate and the incubation continued.

Table 6. Direct actinomycete attack on mycelium of Fusarium culmorum on $A S$ solution agar media

\begin{tabular}{|c|c|c|c|c|c|c|c|c|}
\hline $\mathrm{K}_{2} \mathrm{HPO}_{4}$ concentration $\ldots$ & \multicolumn{4}{|c|}{$0.005 \mathrm{~g} . / \mathrm{l}$} & \multicolumn{4}{|c|}{$0.5 \mathrm{~g} . / 1}$. \\
\hline $\begin{array}{l}\text { Glucose concentration } \ldots \\
\mathrm{C}: \mathrm{N} \text { ratio (nitrate concentration }\end{array}$ & \multicolumn{2}{|c|}{$0 \cdot 1$ g./l. } & \multicolumn{2}{|c|}{$10 \mathrm{~g} . / \mathrm{l}}$. & \multicolumn{2}{|c|}{$0.1 \mathrm{~g} . / \mathrm{l}$} & \multicolumn{2}{|c|}{$10 \mathrm{~g} . / \mathrm{l}}$. \\
\hline adjusted) $\quad \ldots \quad \ldots$ & $\mathbf{5}$ & 40 & 5 & 40 & $\mathbf{5}$ & 40 & 5 & 40 \\
\hline A. No clay & - & - & $\begin{array}{c}+ \\
5 \cdot 3\end{array}$ & $\begin{array}{c}+ \\
4.8\end{array}$ & - & - & - & - \\
\hline B. Agar medium + bentonite & - & - & $\begin{array}{l}+ \\
1 \cdot 25\end{array}$ & - & - & - & - & - \\
\hline C. Agar medium + Broadbalk clay & - & - & $\begin{array}{l}+ \\
1 \cdot 0\end{array}$ & $\stackrel{+}{+}$ & - & - & - & - \\
\hline
\end{tabular}

$-=$ no attack on the fungus; $+=$ direct attack on fungus mycelium as shown by loss of staining properties near actinomycete colonies. Figures give mean width (mm.) of nonstaining zones.

The plates were kept under observation for 3 weeks; during this time no attack on the fungus was seen. However, when each plate was flooded with acetic acid-aniline blue stain, allowed to stand for $1 \mathrm{hr}$. and then washed with water, it was obvious that attack had developed but only on media containing $10 \mathrm{~g}$. glucose/l. and very little phosphate. In no case did the actinomycete grow directly on the fungus mycelium but each actinomycete colony was surrounded by a clear zone in which the fungus hyphae did not take up the stain. These unstained hyphae were apparently devoid of contents although the 
hyphal walls were intact. This partial lysis was prevented or very much reduced (as judged by the widths of the clear zones) when clay was present.

Direct attack by Streptomyces albidoflavus on hyphae of Fusarium culmorum, as had been noticed in sand culture, also took place in water. Washed minute discrete colonies of $F$. culmorum (prepared by growing in glucose asparagine solution agitated on a slow-speed shaker for $40 \mathrm{hr}$.) were suspended in distilled water and incubated with an inoculum of Streptomyces albidoflavus. The actinomycete developed luxuriantly on the fungus mycelium during the first 10 days. After about 3 weeks very little fungus mycelium capable of taking up acetic acid-aniline blue was found though it appeared that the walls of this mycelium had not been attacked. In similar cultures containing bentonite (1 mg. or $10 \mathrm{mg}$./l. culture) the actinomycete was less intimately associated with the fungus and the staining properties of the latter were almost unimpaired. Probably the same agent (e.g. an enzyme readily adsorbed by bentonite and other clays) was responsible both for the partial lysis on agar media and for the direct attack on the fungus in aqueous suspension.

The possibility that the lytic agent was also the antibiotic was then investigated. One $\mathrm{ml}$. portions of a suspension of minute fungus colonies, prepared as described above, were added to $5 \mathrm{ml}$. portions of: $(a)$ sterile water; $(b)$ filtrates of liquid Streptomyces albidoflavus cultures (glucose asparagine solution); (c) heated culture filtrates. Duplicate tubes were incubated and samples removed at intervals (up to 3 weeks) for microscopic examination. In the water tubes the contents of the fungus hyphae were almost entirely stainable with acetic acid-aniline blue though some parts of the hyphae had lost their ability to take up this stain. The condition of the fungus in the unheated and heated culture filtrates was essentially the same as in water. Thus there was no evidence that any lytic substance was present in the filtrates, even though they contained sufficient antibiotic to prevent any new growth of the fungus. It seemed, therefore, from these results, and from those of the experiment in which strong direct attack had taken place on the fungus in water (i.e. under conditions of nutrition unlikely to favour antibiotic production), that the antibiotic and the lytic agent were different substances.

\section{DISCUSSION}

In sand culture the addition of bentonite and other clays decreased but did not prevent the inhibition of growth of Fusarium culmorum by Streptomyces albidoflavus. This indicated that the inhibitory effect of the actinomycete in sand was only in part due to antibiotic action, since bentonite inactivated the antibiotic in the amounts used. Inhibition in the presence of bentonite may reasonably be attributed to competition between the organisms for limiting nutrients. However, it cannot be asserted that competition for nutrients was as important in sand cultures, where the antibiotic was already suppressing growth of the fungus to an extent depending on nutrient conditions, as it was in the sand + bentonite cultures where antibiotic action had undoubtedly been checked by the clay. A lysis of the contents of fungus 
hyphae by actinomycete mycelium in contact with it was observed in sand culture. This lytic attack which could also be demonstrated in aqueous suspensions of the fungus and on agar media, was always prevented or greatly reduced by bentonite which, presumably, adsorbed the lytic agent.

In sand cultures there was a direct relation between the amount of glucose supplied and the antagonistic effects of the actinomycete (Skinner, 1956). This relation was also found when bentonite was added to the sand, so a high concentration of glucose presumably increased competition for limiting nutrients as well as influencing the production of antibiotic secretions. Rapid growth of one organism because of the presence of abundant glucose probably leads to exhaustion of one or more of the other nutrients (e.g. $\mathbf{N}$ source, phosphate) and in this way limits development of the other organisms. This exhaustion did not apparently take place when glucose was present in low concentration. In this sense, competition for nutrients is likely to be more severe when energy-yielding materials are abundant than when they are relatively scarce.

Lysis of the fungus mycelium was also most evident at high concentrations of glucose. The experiment in which fungus mycelium suspended in water was attacked readily by the actinomycete suggests that production of the lytic agent was not directly dependent on the presence of a high concentration of glucose but was determined primarily by the presence of the mycelium itself. However, production of mycelium is favoured by adequate supplies of glucose. At low concentrations of glucose, even when maintained by successive additions, very little inhibition of the fungus by the actinomycete (due to antibiotic activity, lytic action or competition for nutrients) or suppression of the actinomycete by the fungus (due presumably to rapid exhaustion of nutrients by the faster-growing fungus) was found even in sand without bentonite; both organisms were then able to survive together, though the growth of both was comparatively poor.

There is evidence (Skinner, Jones \& Mollison, 1952) that micro-organisms exist mainly as very small colonies in soil, and that the luxuriant growth of any one viable unit (e.g. a spore, vegetative cell or a fragment of mycelium) may be comparatively rare. Soil conditions seem to approximate to those in the experimental cultures in which nutrient concentrations are low, i.e. when both organisms are able to grow together slowly under nutrient conditions unfavourable to the rapid and luxuriant growth of either. It may well be that in soil so many different organisms are able to co-exist because the nutrient conditions are generally unfavourable to the rapid growth of any one of them, i.e. growth is suppressed below the degree at which nutrients are rapidly exhausted and at which production of antibiotics, and lysis, etc., can become effective. The failure to demonstrate antibiotic action in sterile soil does not preclude the possibility that Streptomyces albidoflavus may sometimes be able, in certain soils, to produce sufficient antibiotic to affect the growth of Fusarium culmorum or other fungi. This consideration applies with equal force to other actinomycetes, many of which produce antibiotics. 
This paper is part of a thesis accepted for the degree of Ph.D. at the University of London, 1953. I wish to thank Dr H. G. Thornton, F.R.S., for his helpful advice throughout the course of this work, Miss Angela Roe for technical assistance and Miss Mabel Dunkley for preparing the typescript. I am also indebted to the Agricultural Research Council for a grant which made possible the initiation of this research.

\section{REFERENCES}

Brian, P. W. (1949). The production of antibiotics by micro-organisms in relation to biological equilibria in soil. Symp. Soc. exp. Biol. 3, 357.

Gottlieb, D. \& Siminoff, P. (1952). The production and role of antibiotics in the soil. II. Chloromycetin. Phytopathology, 42, 91.

Jefferys, E. G. (1952). The stability of antibiotics in soils. J. gen. Microbiol. 7, 295.

Pramer, D. \& Starkey, R. L. (1950). The determination of streptomycin in soil. Bact. Proc. no. 18.

Siminoff, P. \& Gotrlieb, D. (1951). The production and role of antibiotics in the soil. I. The fate of streptomycin. Phytopathology, 41, 420.

Skinner, F. A. (1950). Preparation of standardized actinomycete colonies. Nature, Lond. 166, 314.

Skinner, F. A. (1956). Inhibition of the growth of fungi by Streptomyces spp. in relation to nutrient conditions. J. gen. Microbiol. 14, 381.

Skinner, F. A., Jones, P. C. T. \& Mollison, J. E. (1952). A comparison of a directand a plate-counting technique for the quantitative estimation of soil microorganisms. J. gen. Microbiol. 6, 261. 